\title{
Reconstructing Foreign Language Teaching: Moving Beyond Methods
}

\author{
Raqib Chowdhury* \\ Faculty of Education, Monash University \\ raqib.chowdhury@monash.edu
}

\begin{abstract}
Despite the growing popularity of eclectic and post-method education, and the freedom they have afforded to language teachers, contemporary teaching realities present newer scenarios that require more than appropriate teaching methods, approaches, or techniques. Today's learners are a new generation of learners whose needs cannot any more be addressed by simply providing access to technology and developing their digital literacy skills. Educators are required to respond to bringing these different needs to the forefront, and to enact our classroom practices in the spirit of providing an equitable form of education for all, regardless of their visible and invisible differences. Such as perspective encourages us to ask whether particular student sub-groups are advantaged or disadvantaged when classrooms are seen as homogeneous. It is important that we plan our teaching practices so that a differentiated classroom environment can be created to facilitate optimum learning outcomes. This article suggests that through the embedded philosophies of respectfulness and responsiveness, a differentiated approach enables us to provide education fairly to all students with prospects of becoming effective citizens of the future.
\end{abstract}

Keywords-differentiated instruction, education equity, foreign language teaching, optimum learning outcomes

\section{INTRODUCTION}

The continued dominance of the foreign language teaching industry is often driven by the profit motives of the intellectual marketplace. A result of this has been the popularisation of certain methods, most of which were developed in wealthy Anglophone countries and founded on the fallacious persistence that anything imported from the West is advanced and effective. Although long discredited, native-speakerism still persists in the form of the wide adoption of such methods. Despite the eventual popularity of eclectic and post-method pedagogies, and the freedom they have afforded to language teachers, contemporary teaching realities present newer scenarios that require more than appropriate methods, approaches, or styles of teaching.
What we require, instead, is a change in our teaching philosophy, an unlearning leading to learning and a cultural change in the teacher's mindset.

We now teach a new generation of learners whose needs cannot any more be addressed by simply providing access to technology and developing their digital literacy skills (Chowdhury, 2019). Despite its wide practice, the idea of one-size-fits-all instruction that is inherent in many methods and post-methods, has been criticised as not just ineffective but socially unjust and inequitable. In our increasingly diversified classrooms, one of our major challenges is to differentiate our instruction so that individual learning needs are addressed in a fair and equitable manner. Post-methods practices that have worked well in certain educational, social and cultural contexts cannot be exported wholesale and used in a country as culturally and linguistically diverse as Indonesia.

One way of differentiating our instruction towards a more responsive pedagogy is by creating optimal learning spaces through flexible grouping, which can facilitate the development of higher order skills and creativity. This paper problematizes the dangers of homogenising and thus oversimplifying the needs of our students as 'typical' EFL learners. It also offer ideas on how to move towards a more dynamic classroom in which diversity is valued through the adoption of a differentiated instruction approach.

\section{DISCUSSION}

\section{Diversity as Strength}

While working within the pressures of a crowded curriculum, teachers often have to devise innovative ways of teaching in order to best serve their students. In the Indonesian context, such intuitive, on-the- spot decision-making is met with additional challenges, such as large classrooms and increasingly diversified learner profiles. A quick but ineffective way of approaching such challenges is to ignore individual differences among learners and making assumptions about their 
"common" learning aspirations. Such practices, however practical, oversimplifies their needs which have changed due to not only technology and socioeconomics, but because of our better understanding through research of learners' various physical and learning abilities, life experiences, learning preferences and varying levels of readiness.

Indonesia is a country of enormous demographic diversity with a population of 264 million (2017), and consisting of more than 300 ethnic groups who speak more than 700 languages. Of them, the majority ethnic group the Javanese make up about $40 \%$ of the total population. This would make one think that Indonesian classrooms in Java are generally homogenous, both culturally and linguistically. This means, it would not be unusual for teachers in Java to often find all students in their classroom belonging to the Javanese ethnic group, and speaking Javanese.

\section{Visible and Invisible Differences}

The large representations of the majority ethnicity and language in Indonesia, however, can belie the enormous but invisible diversity that often characterise its classrooms. In addition to age group, ethnicity and first language (L1) status, some of the other 'visible' variables can include students' socio-economic status, their giftedness as learners, emotional health, behaviour, access to technology and digital divide, leadership qualities, personal interests and hobbies, and cognitive and physical dis(abilities). However, when we take into account learning theories and research into how teaching and learning happen, many other 'invisible' factors surface; factors that account for certain 'invisible' but significant differences among our learners.

Two of these theories are Gardner's multiple intelligence theories (1983) and Fleming and Mills' learning styles, often referred to as the VARK Model (1992). Together, these, rather than the ethnic or linguistic differences presented above, construct some of the most significant determinants that mark differences among learners in our classrooms. In turn, these differences necessitate adaptations to our teaching styles and approaches, which we often ignore in the name of equal treatment of our students.

Gardner's multiple intelligence theory specifies eight distinct forms of intelligence each individual possesses to a different degree: linguistic, logic/mathematical, musical, spatial, bodily/kinaesthetic, interpersonal, intrapersonal, naturalistic. In addition, Fleming and Mills showed that depending on how students learn, they can be divided into three broad categories - visual learners, auditory learners and Tactile (or Kinaesthetic) learners. A research study conducted at the University of Illinois in 2009 showed that the population is made up of $65 \%$ percent visual learners and only $10 \%$ percent auditory learners. Despite this, $80 \%$ of our teaching instruction in the classroom is delivered orally, which essentially discounts learning styles of many of our students, thereby not allowing us to invest in their strengths.

The instructional implications for multiple intelligence theory are various. For example, it says that teaching and learning should focus on the strength (particular intelligences) of each person and assessment of learning should measure all forms, not just specific ones. It recognises that all learners have strengths - that individuals should be encouraged to use their preferred intelligences in learning. Finally, and perhaps most importantly, it states that assessment should measure multiple forms of intelligence. Practically this would mean more formative and less summative assessment in the classroom. Summative assessment tasks, often referred to as assessment of learning, are formal, structured and graded/quantifiable. These are important to determine student learning outcomes and to prepare student reports. On the other hand, formative assessment, or assessment for learning, is informal and ongoing, almost always unstructured, and includes selfand peer-assessment. Because of its relaxed and unstudied nature, students benefit from feedback from both teachers and peers and are likely to learn more from such feedback.

As educators it is our responsibility to respond to bringing these invisible differences to the forefront, and to enact our classroom practices in the spirit of providing an equitable form of education for all learners, regardless of their visible and invisible differences. However, instead, as teachers we often resort to the convenience of homogenising the needs of our students, labelling them as 'typical' learners with 'typical' needs. Such homogenising practices, after all, make it easier for us to plan and conduct our teaching and assessment. It also saves us time and is less resource-intense.

Homogenising the needs of our students as 'typical' learners can do a great disservice to their learning. We live in a time when a one-size-fits-all approach to teaching is seen as socially unjust and inequitable. Based 
on the principles of social justice and equity, one way of offering a more responsive approach to teaching is through differentiated instruction - an approach that allows teachers to accommodate students' diverse learning needs by acknowledging and respecting their individual differences. In order to provide equitable learning opportunities, we need to move our teaching practices from a "one size fits all" approach to curriculum and instruction that does not fit everyone; one that matches what is offered with what is needed.

Such a perspective is based on the notion of social justice, where equity is more important than equality. Such as perspective encourages us to ask - are particular student sub-groups advantaged or disadvantaged when classrooms are seen as homogeneous?

Differentiated Instruction through Flexible Grouping Contemporary research in education has placed a lot of emphasis on the importance of providing equitable (rather than equal) education for all. Differentiated instruction to teaching - which encompasses adapting our teaching styles and approaches to individual students' needs - offers different approaches to content, process, and product, but with the same goal. In other words, instead of offering harder tasks to high performing students and 'dumbing down' learning for students who find it difficult, a differentiated approach to instruction creates multiple paths to the same goal for everyone in the class, regardless of their perceived abilities.

Such goals can be achieved, among other things, through flexible grouping and flexible assessment. Tomlinson suggests what she calls the "ebb and flow of experiences model" (1999) which allows teachers to group students differently so that they are appropriately challenged at all times. While rigid grouping can label a student's readiness as static, movement between groups responds to the change in interest among learners and creates greater opportunities for students to face the high challenge that Mariani (1997) sees as essential in the learning process.

Various groups can be formed within this ebb and flow of experiences. For example, homogenous ability grouping clusters students with similar abilities, interests and learning styles together, while heterogeneous grouping makes students of different abilities, levels, learning styles and interests to work together. The latter grouping is known to promote creativity and enhance confidence among learners. Such grouping also facilitates optimum conditions for peerscaffolding which can be done when students interact and engage in activities. Tomlinson's model also provides options for self-paced learning in which individual learners engage in independent study - an arrangement that encourages skills such as time management and task responsibility.

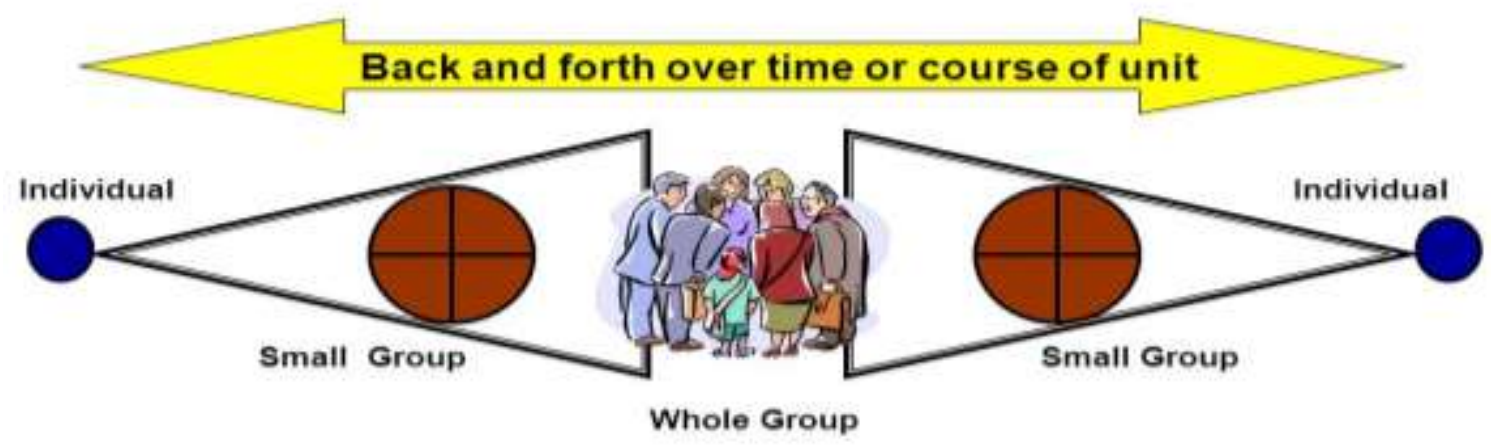

Figure 1. The Ebb and flow of Experiences, Tomlinson, 1999

The enactment of differentiated instruction through such flexible grouping is respectful teaching. According to Tomlinson (2000, P. 1):

Differentiation consists of the efforts of teachers to respond to variance among learners in the classroom. Whenever a teacher reaches to an individual or small group to vary his or her teaching in order to create the best learning experience possible, that teacher is differentiating instruction.

Noteworthy is that differentiated instruction, unlike, say the communicative language teaching, or task-based 
language teaching, is not a pedagogy, nor is it a method. It is a way of thinking about teaching and learning (Tomlinson, 2010). After all, "If we only learn methods, we are tied to those methods, but if we learn principles, we can develop our own methods." (Emerson, 1871). The benefits of differentiated instruction are numerous, its respectful nature makes students feel valued as individuals, thereby encouraging them to achieve goals and progress at their own pace. It promotes the spirit of tolerance and appreciation of differences. Looking beyond the reductive view of literacies as limited to reading and writing, it emphasises on the notion of multi-literacies by making teaching and learning multidimensional, multisensory and multimodal.

Perhaps more importantly at the practical level, differentiated instruction can be practised without meeting the demands of the latest technology or abundant resources, and in large classrooms such as those in Indonesia. It enables us to devise practical ways of providing equitable, socially just and fair learning opportunities to all students in a manner in which diversity is valued through the adoption of a differentiated instruction approach. It is important that we plan our teaching practices so that a differentiated classroom environment can be created, one that facilitates optimum learning for all and one that is also responsive to the contextual logistics of classrooms in Indonesia at a time of great academic diversity.

\section{REFERENCES}

Chowdhury, R. (2019). Transformation through education in contemporary times: A Freirean reconsideration. In R. Chowdhury (Ed.) Transformation and Empowerment through Education: Reconstructing Teaching and Learning (pp. 1-16). London: Routledge.

Fleming, N. D. (2006). V.A.R.K Visual, Aural/Auditory, Read/Write, Kinesthetic. New Zealand: Bonwell Green Mountain Falls.

Fleming, N. D., \& Baume, D. (2006). Learning styles again: VARKing up the right tree! Educational Developments. 7(4), 4-7.

\section{CONCLUSION}

Being good at taking standardized tests does not qualify students for creative contribution to society or successful citizenship. We need to question if standards reflect the knowledge, understandings, and skills valued most our society; whether we are perfunctorily responding to standards or the sake of ticking boxes of compliances, or whether we have devised ways to rethink the standards in our curriculum, teaching and assessment so that our learners have time to make sense of their learning. Through the embedded philosophies of respectfulness and responsiveness, a differentiated approach to teaching enables us to provide education fairly to all of our students with prospects of becoming effective citizens of the future.

Far from being a Western construct, social justice - the philosophy which underpins differentiated instruction is a quintessentially Indonesian attribute embedded within the construct of Pancasila and the notion of Bhinneka Tunggal Ika. Rather than through cutting-edge technologies, imported pedagogies and overseas teaching qualifications, the EFL environment in Indonesia will no doubt benefit much from adopting a balanced approach between individualised instruction and teaching uniformly through an adoption and exercise of differentiated instruction in a time of great academic diversity in its classrooms.

Fleming, N. D., \& Mills, C. (1992). Not another inventory, rather a catalyst for reflection. To Improve the Academy, 11, 137-155.

Gardner, H. (2006). Multiple intelligences: New horizons in theory and practice. New York: Basic Books.

Mariani, L. (1997). Teacher support and teacher challenge in promoting learner autonomy. Perspectives, a Journal of TESOL-Italy, 23(2).

Tomlinson, C. (1999). The differentiated classroom: Responding to the needs of all learners. Alexandria, VA: Association for Supervision and Curriculum Development. 